\title{
Effects of Acute Exposure to Cadmium on the Electrolyte Balance in Plasma of the Carp and Girella
}

\author{
Ryosuke Kuroshima* \\ (Received December 6, 1991)
}

\begin{abstract}
The effects of cadmium exposure on the concentrations of blood plasma electrolytes (sodium, potassium, calcium, and magnesium) in the carp Cyprinus carpio and the girella Girella punctata were examined.

In the carp, all four electrolytes examined decreased significantly after $24-\mathrm{h}$ exposure to $0.3 \mathrm{mg}$ $\mathrm{Cd} / l$. The total calcium concentration in plasma decreased significantly during the camdium exposure. The depression of the total calcium concentration in plasma depended on the ambient cadmium concentration. The total magnesium concentration in plasma increased significantly after a transient decrease.

In the girella, the plasma concentrations of sodium and total magnesium increased significantly and the concentrations of potassium and total calcium showed a tendency to decrease during the exposure to $10 \mathrm{mg} \mathrm{Cd} / l$. However, the decrease of the total calcium and potassium concentrations in plasma did not necessarily depend on the cadmium concentration in the seawater.

The results of the study suggest that cadmium of high concentrations could increase the electrolyte permeability of the apical plasma membrane of the obsorption site, and that the uptake of potassium and calcium from water into the body of fish could be particularly inhibited by lower cadmium concentrations.
\end{abstract}

Concentrations of various blood plasma electrolytes in freshwater fish are regulated under processes of the absorption of electrolytes from water by active transport mechanisms, the control of water permeability of the body surface, and the selective reabsorption of electrolytes from urine. It is known that the exposure of freshwater fish to a heavy metal results in disturbed electrolyte balance. For example, changes in the plasma electrolyte composition have been observed in

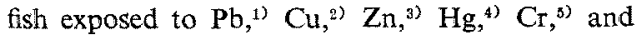
Cd. ${ }^{\text {e) }}$

The plasma electrolyte concentrations in saltwater fish are regulated by a different mechanism from that of freshwater fish. Hence, it can be expected that the effect of a heavy metal on the plasma electrolyte composition is different between freshwater and saltwater fish.

The purpose of the present study was to compare the disturbed electrolyte balance in the carp Cyprinus carpio and the girella Girella punctata after cadmium exposure.

\section{Materials and Methods}

\section{Experiment 1}

The effect of the time of cadmium exposure on the concentrations of plasma electrolytes (sodium, potassium, calcium, and magnesium) in the carp (body weight: $36-58 \mathrm{~g}$ ) and the girella (body weight: $62-131 \mathrm{~g}$ ) was examined. The concentrations of cadmium in the test water were $0.3 \mathrm{mg} \mathrm{Cd} / l$ for the carp and $10 \mathrm{mg} \mathrm{Cd} / l$ for the girella. Thirty-five fish were divided into seven groups consiting of five fish each and exposed to cadmium in $20 l$ glass aquaria aerated throughout the experimental period. The temperature was $23.6 \pm 0.5^{\circ} \mathrm{C}$. The freshwater for the carp was tap water dechlorinated by aeration $(\mathrm{Na}, 0.13$ $\mathrm{mM}$; K, $0.05 \mathrm{mM}$; $\mathrm{Ca}, 0.40 \mathrm{~mm} ; \mathrm{Mg}, 0.23 \mathrm{mM}$ ) and the girella were kept in seawater filtered throught activated charcoal $(\mathrm{Na}, 413 \mathrm{~mm} ; \mathrm{K}$, $11.5 \mathrm{~mm} ; \mathrm{Ca}, 10.0 \mathrm{~mm} ; \mathrm{Mg}, 49.4 \mathrm{~mm})$. Six groups were sampled at $0,4,24,48,96$, and $192 \mathrm{~h}$ during the exposure, and one group was sampled after 96-h depuration in cadmium-free seawater following 96-h exposure. Fish were not fed during the test period.

Blood was centrifuged at $10,000 \mathrm{rpm}$ for $5 \mathrm{~min}$ at room temperature before the coagulation, immediately after collecting from the caudal artery by syringe. Plasma samples of fish were directly diluted with distilled water to determine concentrations of electrolytes by atomic absorp-

\footnotetext{
* Arasaki Marine Biological Station, National Research Institute of Fisheries Science, Nagai, Yokosuka,
} Kanagawa, 238-03, Japan (黒岛良介：中央水産研究所 環境保全部). 
tion spectrometry.

This experiment was performed in May, 1991.

\section{Experiment 2}

The effect of the ambient cadmium concentration on plasma electrolytes in the carp (body weight: $27-47 \mathrm{~g}$ ) and girella (body weight: 55$103 \mathrm{~g}$ ) was examined. Thirty fish were divided into six groups consisting of five fish each. Carp were exposed to $0,0.01,0.03,0.1,0.3$, and $0.6 \mathrm{mg}$ $\mathrm{Cd} / l$ and girella to $0,0.3,1,3,10$, and $20 \mathrm{mg}$ $\mathrm{Cd} / l$ in $20 l$ aquaria for $96 \mathrm{~h}$. The other experimental conditions and analytical methods for plasma electrolytes were as in experiment 1 .

This experiment was performed in October, 1991.

In seawater, cadmium becomes closely associated with chloride ions and the $\mathrm{LC}_{50}$ value to fish is higher than in freshwater, as a rule. Therefore, the concentrations of cadmium in the test water for the girella were designed to be much higher than for the carp in the present study.

\section{Results}

Experiment 1

One carp died during the 96-h exposure, and
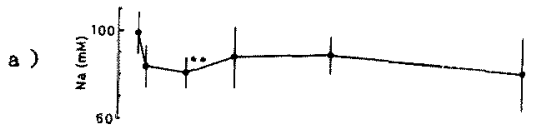

b )

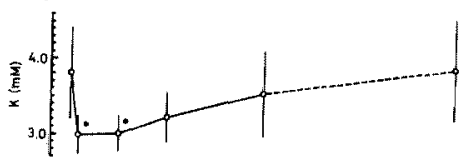

c)

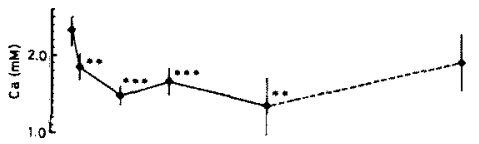

d )

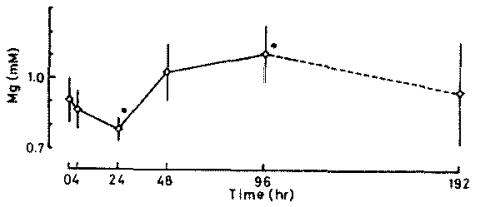

Fig. 1. Changes in electrolyte concentrations in blood plasma of carp during exposure to $0.3 \mathrm{mg}$ $\mathrm{Cd} / l$.

Dotted line indicates the $96-\mathrm{h}$ depuration in cadmium-free seawater following 96-h exposure. a) sodium, b) potassium, c) calcium, and d) magnesium. Values are means $\pm S D$ for five fish.

$$
{ }^{*}, p<0.05 ; * *, p<0.01 ; * * *, p<0.001 \text {. }
$$

none of them survived $192 \mathrm{~h}$ of exposure. Three girellas died during the test period, and the supplemental fish were exposed to cadmium under the same conditions as in the first experiment in order to make up for the short number of plasma samples.

Changes in plasma electrolytes with time are shown in Figs. 1 and 2. The plasma sodium concentration in the carp exposed to $0.3 \mathrm{mg}$ $\mathrm{Cd} / l$ showed a tendency to decrease. The concentration after $24 \mathrm{~h}$ was significantly lower than the initial concentration. The $96-\mathrm{h}$ depuration in cadmium-free water after the $96-\mathrm{h}$ exposure had no effect on this. In the girella, the exposure to $10 \mathrm{mg} \mathrm{Cd} / l$ caused a significant increase in the concentration of plasma sodium. The 96-h depuration resulted in its recovery to the initial level.

The plasma potassium concentration in the exposed carp decreased rapidly, and the values after 4 and $24 \mathrm{~h}$ were significantly lower than the initial value. Thereafter, it showed a tendency to recover to the initial level. The concentration after the $96-\mathrm{h}$ depuration was roughly the same as

a )

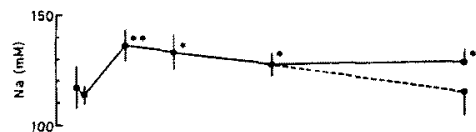

b )

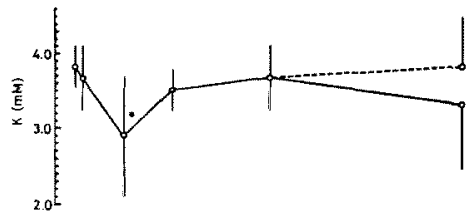

c)

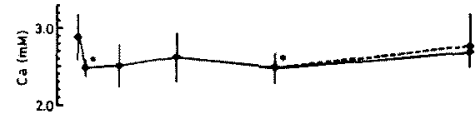

d)

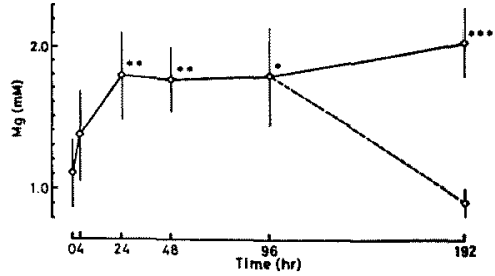

Fig. 2. Changes in electrolyte concentrations in blood plasma of girella during exposure to $10 \mathrm{mg}$ $\mathrm{Cd} / l$.

Dotted line indicates the 96 -h depuration in cadmium-free seawater following $96-\mathrm{h}$ exposure. a) sodium, b) potassium, c) calcium, and d) magnesium. Values are means $\pm \mathrm{SD}$ for five fish. ${ }^{*}, p<0.05$; $^{* *}, p<0.01 ; * * *, p<0.001$ 
the initial concentration. In the exposed girella, the plasma potassium concentration showed a tendency to decrease. The concentration after $24 \mathrm{~h}$ was significantly lower than the initial concentration. The value after the 96-h depuration showed roughly the same as the initial concentration.

The total calcium concentration in the plasma of the exposed carp decreased significantly during the cadmium exposure. After the 96-h depuration in cadmium-free water, the total calcium concentration recovered to a level not significantly different from the initial concentration. In the exposed girella, the total calcium concentration in plasma showed a tendency to decrease during the exposure. The concentrations after 4 and $96 \mathrm{~h}$ were significantly lower than the initial concentration. The value after $192 \mathrm{~h}$ of exposure was at roughly the same level as that after the 96-h depuration following 96-h exposure.

The total magnesium concentration in the plasma of exposed carp showed a significant decrease after $24 \mathrm{~h}$, but it increased to a level significantly higher than the initial concentration after $96 \mathrm{~h}$. The concentration after the $96-\mathrm{h}$ depuration was roughly at the same level as the initial value. In the exposed girella, the total magnesium concentration in plasma increased significantly during the cadmium exposure. After the 96-h depuration in cadmium-free seawater, the concentration repidly recovered to the initial level.

\section{Experiment 2}

The changes in electrolyte concentrations in the plasma of carp and girella exposed to various concentrations of cadmium for $96 \mathrm{~h}$ are shown in Figs. 3 and 4. Reduced plzsma sodium concentration was observed only in the carp exposed to $0.6 \mathrm{mg} \mathrm{Cd} / l$ for $96 \mathrm{~h}$. Increased plasma sodium concentration was found only in the girella exposed to $20 \mathrm{mg} \mathrm{Cd} / l$ for $96 \mathrm{~h}$.

The plasma potassium concentration in the carp significantly decreased after the 96-h exposure to 0.3 and $0.6 \mathrm{mg} \mathrm{Cd} / l$. The average concentration of plasma potassium in the carp exposed to $0.6 \mathrm{mg} \mathrm{Cd} / l$ was the lowest. In the girella, the plasma potassium concentration decreased significantly after the 96-h exposure to 3 and $10 \mathrm{mg}$ $\mathrm{Cd} / l$, but no significant difference was found after exposure to $20 \mathrm{mg} \mathrm{Cd} / l$. The average concentration of plasma potassium in the girella exposed to $3 \mathrm{mg} \mathrm{Cd} / l$ was the lowest.

The total calcium concentration in the plasma a )

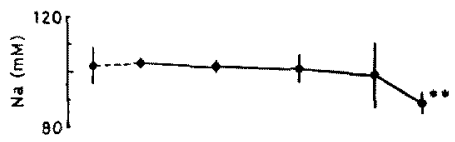

b)

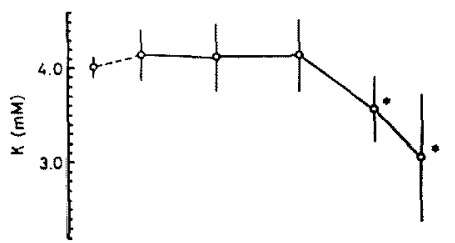

c )

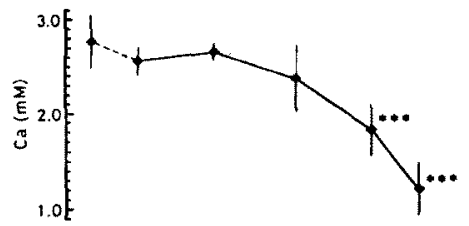

d )

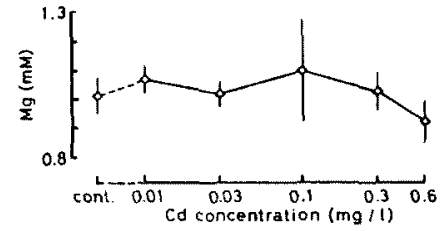

Fig. 3. Electrolyte concentrations in blood plasma of carp exposed to various concentrations of cadmium for $96 \mathrm{~h}$.

a) sodium, b) potassium, c) calcium, d) magnesium. Values are means $\pm S D$ for five fish.

*, $p<0.05$; **, $p<0.01$; ***, $p<0.001$.

of the carp decreased significantly after the 96-h exposure, to 0.3 and $0.6 \mathrm{mg} \mathrm{Cd} / l$. The average concentration of total plasma calcium in the carp exposed to $0.6 \mathrm{mg} \mathrm{Cd} / l$ was the lowest. In the girella, the total calcium concentration in the plasma decreased as the cadmium concentrations below $10 \mathrm{mg} \mathrm{Cd} / l$ increased. The total calcium concentration in the plasma of the girella exposed to $20 \mathrm{mg} \mathrm{Cd} / l$ for $96 \mathrm{~h}$ was significantly lower than the control value, but it was higher than that in the fish exposed to $1 \mathrm{mg} \mathrm{Cd} / l$ for $96 \mathrm{~h}$.

The total magnesium concentration in the plasma of the carp did not show any change after the 96-h exposure to various cadmium concentrations. In the girelia, the total magnesium concentration in plasma increased significantly after the 96-h exposure to 1 and $20 \mathrm{mg} \mathrm{Cd} / l$ but not after exposure to 3 and $10 \mathrm{mg} \mathrm{Cd} / l$.

\section{Discussion}

The plasma sodium concentration in the carp decreased initially during the exposure to 0.3 
a)

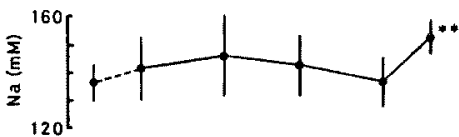

b )

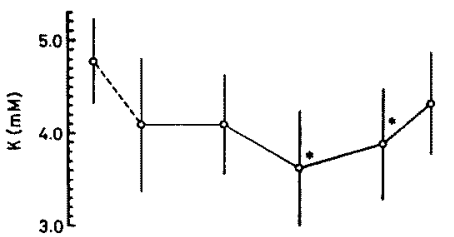

c )

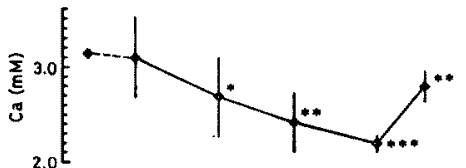

d )

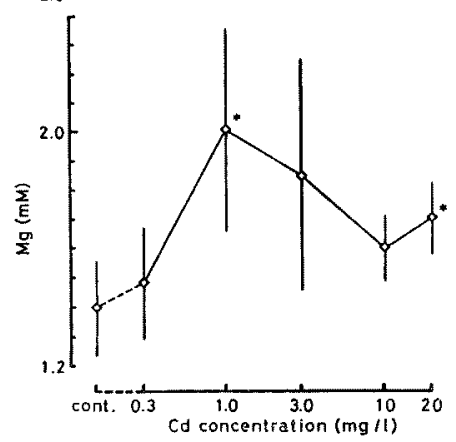

Fig. 4. Electrolyte concentrations in blood plasma of girella exposed to various concentrations of cadmium for $96 \mathrm{~h}$.

a) sodium, b) potassium, c) calcium, and d) magnesium. Values are means $\pm S D$ for five fish.

${ }^{*}, p<0.05 ; * *, p<0.01 ;{ }^{* * *}, p<0.001$.

mg Cd/l (Fig. 1-a), while the plasma sodium concentration in the girella increased during the exposure to $10 \mathrm{mg} \mathrm{Cd} / \mathrm{l}$ (Fig. 2-a). Since the sodium concentration in the plasma of fish is higher than the concentration in freshwater and lower than that in seawater, the changes in the plasma sodium concentration during cadmium exposure could be attributed to the increase in sodium permeability of the gill epitherlium. High cadmium concentrations are known to increase the electrolyte permeability of the plasma membrane of the blood cells. ${ }^{8, \theta)}$ The plasma sodium concentrations in the carp exposed to below $0.3 \mathrm{mg} \mathrm{Cd} / l$ for $96 \mathrm{~h}$ were at roughly the same level (Fig. 3-a), and this could be caused by homeostasis to compensate for the disturbance of electrolytes in their bodies. Although the plasma sodium concentration in the girella exposed to $10 \mathrm{mg} \mathrm{Cd} / l$ increased in experiment 1, the plasma sodium concentration in the girella exposed to $10 \mathrm{mg} \mathrm{Cd} / l$ in experiment 2 was not significantly different from the control level (Fig. 4-a). This may be due to the higher plasma concentration of sodium $(137 \mathrm{~mm})$ in the control girella in experiment 2 than the concentration at $0 \mathrm{~h}(117 \mathrm{~mm})$ in experiment 1.

The plasma potassium concentrations in the carp exposed to $0.3 \mathrm{mg} \mathrm{Cd} / l$ and the girella exposed to $10 \mathrm{mg} \mathrm{Cd} / l$ decreased initially during the test period (Figs. 1-b and 2-b). The hypokalemia in the girella cannot be explained only by the increase in the permeability of the gill epithelium, since the girella were exposed to cadmium in the seawater with a potassium concentration about three times higher than the concentration in their blood plasma. In experiment 2, the lowest plasma potassium level was found in the carp exposed to $0.6 \mathrm{mg} \mathrm{Cd} / l$ for $96 \mathrm{~h}$ (Fig. 3-b) and in the girella exposed to $3 \mathrm{mg} \mathrm{Cd} / l$ for $96 \mathrm{~h}$. The plasma potassium concentration in the girella exposed to $20 \mathrm{mg} \mathrm{Cd} / l$ for $96 \mathrm{~h}$ was not significantly different from the control level (Fig. 4-b). These results suggest that cadmium may inhibit the influx of potassium at the absorption site of the gills, intestine, and body surface, besides the effect of increasing the potassium permeability of the plasma membrane. It has been reported that the absorptive process may be energized by an apical membrane $\mathrm{K}, \mathrm{H}$-ATPase, ${ }^{10)}$ but the cadmium effect on potassium absorption process has not been studied.

The total calcium concentration in plasma exposed to $0.3 \mathrm{mg} \mathrm{Cd} / l$ decreased rapidly (Fig. 1-c), and the concentration in the girella exposed to $10 \mathrm{mg} \mathrm{Cd} / l$ showed a tendency to decrease during the test period (Fig. 2-c). It is well established that freshwater fish take up most of the calcium necessary for growth and calcium homeostasis from the water via their gills. ${ }^{11,12}$ ) Therefore, it is possible that the hypocalcemia induced by cadmium in freshwater fish is caused mainly by inhibiton of calcium uptake via the gills. ${ }^{13,14)}$ In experiment 2 , the lowest concentration of the total calcium in plasma was found in the carp exposed to $0.6 \mathrm{mg} \mathrm{Cd} / l$ for $96 \mathrm{~h}$ (Fig. 3-c) and in the girella exposed to $10 \mathrm{mg}$ $\mathrm{Cd} / l$ for $96 \mathrm{~h}$. These results suggest that calcium influx into the body of saltwater fish could be inhibited by cadmium as well as the active uptake of calcium in freshwater fish. Since the ambient calcium concentration in seawater is higher than 
the cytoplasmic levels, it is likely that the large calcium gradient causes calcium to enter the cells across the apical membrane via a passive diffusion process. In most non-excitable cells, facilitated diffusion appears to be the primary mechanism of calcium entry. ${ }^{15)}$ Although the calcium carrier involved in the facilitated diffusion of calcium into cells has not yet been identified, it was proposed that cadmium with nearly the same ionic size as calcium could compete readily for calcium-binding sites on membrance carrier proteins. ${ }^{16)}$ On the other hand, the total calcium concentration in plasma of the girella exposed to $20 \mathrm{mg} \mathrm{Cd} / l$ for $96 \mathrm{~h}$ was $2.79 \mathrm{mM}$, which is higher than the $2.67 \mathrm{~mm}$ in the fish exposed to $1 \mathrm{mg} \mathrm{Cd} / \mathrm{l}$ for $96 \mathrm{~h}$. This result suggests that the high cadmium concentrations increased the calcium permeability of the plasma membrane. Cadmium seems to have biphasic effects in the transporation of electrolytes across the plasma membrane.

The total magnesium concentration in the plasma of the carp exposed to $0.3 \mathrm{mg} \mathrm{Cd} / \mathrm{l}$ increased significantly after the initial decrease (Fig. 1-d) and the concentration in the girella exposed to $10 \mathrm{mg} \mathrm{Cd} / l$ increased rapidly (Fig. 2-d). The hypermagnesemia in the carp culd be the secondary effect of cadmium to its effect on calcium. Experimental changes in plasma calcium concentrations in mammals are often associated with changes in magnesium. ${ }^{\text {) }}$ The rapid increase of the total magnesium concentration in the plasma of girella could be attributed to an increase in the permeability of the gill epithelium. Since seawater contains an approximately 44 times higher magnesium concentration than the blood plasma of fish, only a slight increase in the membrane permeability apparently caused the significant change in the total magnesium concentration in plasma of the girella. The rapid recovery from hypernatremia, hyperkalemia, and hypermagnesemia in the exposed girella after the 96-h depuration suggests that the cadmiuminduced change in the permeability of plasma membrane was reversible. It is unknown why hypermagnesemia was not observed in the carp exposed to cadmium at any concentration for $96 \mathrm{~h}$ in experiment 2 (Fig. 3-d). The total magnesium concentration in the plasma of the girella exposed to 3 and $10 \mathrm{mg} \mathrm{Cd} / l$ for $96 \mathrm{~h}$ in experiment 2 did not show a significant difference from the control (Fig. 4-d). This may be due to the higher concentration of total plasma magnesium in the control girella in experiment $2(1.40 \mathrm{~mm})$ than that at $0 \mathrm{~h}$ in experiment $1(1.11 \mathrm{~mm})$.

The kidney is one of the most important organs for blood electrolyte regulation. and it is also known as the target organ of cadmium. Degenerative, cadmium induced renal changes have been reported for mammals ${ }^{17-10)}$ and for fish. ${ }^{20)}$ However, the results from the study to investigate the electrolyte and water balance in plasma and urine of rainbow trout during chronic exposure to cadmium demonstrated that the majority of cadmium-induced electrolyte imbalances did not result from impairment of renal function. ${ }^{21}$ )

In saltwater fish, the intestines are involved in electrolyte and water handling. Since saltwater fish drink ambient water for their osmoregulation, it is possible that cadmium in seawater has a direct effect on the function of the intestinal epithelium. Further investigation from this viewpoint is needed in order to clarify the effect of cadmium on the electrolyte balance in fish.

\section{References}

1) G. Christensen, E. Hunt, and J. Fiandt: The effect of metylmercuric chloride, cadmium chloride and lead nitrate on six biochemical factors of the brook trout (Salvelinus fontinalis). Toxicol. Appl. Pharmacol., 42, 523-530 (1977).

2) S. D. Lewis and W. M. Lewis: The effect of zinc and copper on the osmolality of blood serum of the channel catish Ictalurus punctatus Refinesque, and the golden shiner Notemigonus crysoleucas Mitchell. Trans. Anter. Fish. Soc., 100, 639-646 (1971).

3) D. J. Spry and C. M. Wood: Ion fux rates, acid-base status, and blood gases in rainbow trout, Salmo gairdneri exposed to toxic zine in natural soft water. Can. J. Fish. Aquat. Sci, 42, 1332-1341 (1985).

4) R. A. C. Loch, P. M. J. M. Cruijsen, and A. P. Van Overbeeke: Effects of mercuric chloride and methylmercuric chloride on the osmoregulatory function of the gills in rainbow trout, Salmo gairdneri Richardson. Comp. Biochem. Physiol., 69C, 151-157 (1981).

5) I. Van der Putte, M. B. H. M. Laurier, and G. J. M. van Eijk: Respiration and osmoregulation in rainbow trout (Salmo gairdneri) exposed to hexavalent chromium at two different pH levels. Aquat. Toxicol., 2, 97-1 12 (1983).

6) H. B. Pratap, H. Fu, R. A. C. Loch, and S. E. Wendelaar Bonga: Effect of water-borne and dietary cadmium on plasma ions of the teleost Orechromis mossambicus in relation to water calcium levels. Arch. Environ. Contam. Toxicol., 18, 568-575 (1987).

7) G. A. Plishker: Effects of cadmium and zinc on calcium uptake in human red blood cells. Am. J. Physiol, 247, C143-C147 (1984).

8) E. M. B. Sorensen, D. Acousta, and D. G. Nealon: Effects of cadmium and calcium on the fluidity of plasma membranes. Toxicol. Lett., 25, 319-326 (1985).

9) E. S. Foster, J. P. Hayslett, and H. J. Binder: Mechanism of active potassium absorption and secretion in rat colon. Am. J. Physiol., 246, G611-G617 (1984).

10) Y. Mugiya and $T$. Ichii: Effects of estradiol-17\% on branchial and intestinal calcium uptake in the rainbow trout, Salmo gairdneri. Comp. Biochem. Physiol, 70A, 98-101 (1981).

11) S. F. Perry and C. M. Wood: Kinetics of branchial calcium 
uptake in the rainbow trout: effects of acclimatization to various external calcium levels. $J$. Exp. Biol., 116, $411-433$ (1985).

12) P. M. Verbost, G. Flik, R. A. C. Lock and S. E. Wendelaar Bonga: Cadmium inhibition of $\mathrm{Ca}^{2+}$ uptake in rainbow trout gills. Amer. J. Physiol, 253, R216-R221 (1987).

13) S. D. Reid and D. G. McDonald: Effects of cadmium, copper, and low $\mathrm{pH}$ on ion fuxes in the rainbow trout, Salmo gairdneri. Can. J. Fish. Aquat. Sci., 45, 244-253 (1988).

14) G. J. Barrit: Calcium movement across the cell membrane. in "The Role of Calcium in Biological Systems" ed. by L. J. Anghileri and A. M. Tuffet-Anghileri, 2, CRC Press, 1982, pp. 17-30.

15) G. R. Sauer and N. Watabe: The effects of heavy metals and metabolic inhibitors on calcium uptake by gills and scales of Fundulus heteroclitus in vitro. Comp. Biochem. Physiol., 91C, 473-478 (1988).

16) H. Ebel and T. Gunther: Magnesium metabolism: A review. J. Clin. Chem. Clin. Biochem., 18, $257-270$ (1980).
17) M. Nishizumi: Electron microscopic study of cadmium nephrotoxicity in the rat. Arch. Environ. Helath, 25, 215225 (1972).

18) R. L. Singhal, Z. Merali, S. Kacew, and D. J. B. Sutherland: Persistence of cadmium-induced metabolic changes in liver and kidney. Science, 183, 1094m1096 (1974).

19) F. N. Kotsonis and C. D. Klaassen: The relationship of metallothionein to the toxicity of cadmium after prolonged oral administration to rats. Toxicol. Appl. Pharmacol., 46, 39-.54 (1978).

20) J. Koyama, M. Fujita, and Y. Itazawa: Effects of ora administration of cadmium on fish-IV. Effects on ultrastructures of hepatic and renal cells of the carp and the porgy. Nippon Suisan Gakkaishi, 45, 429-436 (1977).

21) M. A. Giles: Electrolyte and water balance in plasma and urine of rainbow trout (Salmo gairdneri) during chronic exposure to cadmium. Can. J. Fish. Aquat. Scl., 41, 16781685 (1984). 